\title{
OPTIMIZED SWITCH ALLOCATION TO IMPROVE THE RESTORATION ENERGY IN DISTRIBUTION SYSTEMS
}

\author{
Hamed H. Dezaki * Hossein A. Abyaneh* \\ Ali Agheli ${ }^{*}$ - Kazem Mazlumi ${ }^{* *}$
}

\begin{abstract}
In distribution networks switching devices play critical role in energy restoration and improving reliability indices. This paper presents a novel objective function to optimally allocate switches in electric power distribution systems. Identifying the optimized location of the switches is a nonlinear programming problem (NLP). In the proposed objective function a new auxiliary function is used to simplify the calculation of the objective function. The output of the auxiliary function is binary. The genetic algorithm (GA) optimization method is used to solve this optimization problem. The proposed method is applied to a real distribution network and the results reveal that the method is successful.
\end{abstract}

Ke y w ords: Power distribution systems, switches, restoration energy, genetic algorithm (GA)

\section{INTRODUCTION}

The main objective of the planning and operation of electric power distribution systems is to satisfy the system load and energy requirements as economically as possible with a reasonable assurance of continuity and quality. The two aspects of relatively low cost electrical energy at a high level of reliability are often in direct conflict due to the fact that providing a higher level of reliability will cost utilities more in capital and operational expenditures. This has become justification to emphasize on the optimization of the system costs and reliability [1].

The optimal placement of the switches and the protective devices is one of the most important parameters in designing power distribution systems. Therefore, there is an increasing interest in optimization of allocation of protective and switching devices in distribution systems and there have been many studies in this regard [2-10]. References $[6,7,11]$ propose different mathematical models and optimization methodologies for optimal placement of protective and switching devices. The objectives of the references are to increase the reliability and to decrease the costs. Several optimization methods have been used to solve such problems as genetic algorithm (GA), ant colony system (ACS), reactive tabu search (RTS), simulation annealing, etc[5-11].

In [9], the optimized placement of protective devices is used to decrease the system average interruption frequency index (SAIFI). Reference [6] Engages with the decreasing of the system cost to determine the optimal device position. The main difference between methods proposed in [11] and [6,9] is using single or multi objective. Reference [11] has determined device placements in distribution system to improve SAIFI, SAIDI and total cost.
Most of the above approaches are mainly theoretical. It means that the application of the optimization results is not feasible for real feeders. In addition, in most of the above references the restoration effect and maneuver by other feeders are omitted. In this paper, the restoration effect is taken into account. The new mathematical model is introduced to calculate the restorative energy while a fault occurs. A new index is introduced to show the energy restoration of the customers called R.I (Restoration Index). A new objective function based on R.I has been developed. The genetic algorithm has been used to optimize the objective function. From the application of the method on a real distribution feeder, the best switch position can be found.

\section{PROBLEM STATEMENT}

It is an interesting subject to increase the reliability indices in distribution systems and decrease the system cost. Hence, researchers try to find suitable solutions obtain these goals. One method to increase the system reliability is finding the optimum placement of devices. Several studies have been carried out about this subject. But, there is not any analytical solution in most studies to optimize the placement of protective or switching devices in distribution systems. Proficiency on all sides of the problem can be achieved when analytical solution is developed for solution. When analytical method is used to solve the problem, method correction investigation is accessible and easy. Hence, new method is introduced in this paper to calculate the energy restoration in distribution systems whose calculation is analytical.

In recent researches concerning the optimization of the device placements, there seems to be two other problems related to the implementation of the optimum results in

\footnotetext{
* Electrical Engineering Department, Amirkabir University of Technology, 15914, Tehran, No. 424, Hafez Ave, Iran, hamed.hashemi@gmail.com; ${ }^{* *}$ Zanjan University, Iran
} 
the system as well as the lack of confidence of the managers to the proposed changes. When results devise the system to change most of device placements, superintendents are reluctant to main changes in the system and do not risk. Most solutions proposed in recent researches emphasize the main changes. Therefore, a practical solution is proposed in this paper.

\section{PROBLEM FORMULATION}

By fault occurrence in distribution networks, several customers experience an interruption. But, with switching device, it can be possible to restore some of them. Although in references [6,7], the main subject is total cost and reliability index, there is brief pointing to energy restoration. The new model is developed to calculate the $R I$ (restoration Index). In Mathematical model of the factors, there is the auxiliary function $A(i, j)$ which might be described as follows in (5). R.I is demonstrated as follows

$$
R I=\sum_{i=1}^{3} \text { factor }(i)
$$

$$
\begin{gathered}
\text { factor }(1)=\sum_{i=1}^{m b} \boldsymbol{X}_{s i}\left(\sum_{j=1}^{m b} \lambda_{m j} A(i, j) \times\right. \\
\sum_{k=1}^{b l b(i)} \sum_{l=1}^{t s(k)} L(k, l) A(f d m b, i-1) \prod_{m=f d m b(k)}^{i-1}\left(1-\boldsymbol{X}_{s m}\right)+ \\
\sum_{n=f l b(1)-f l b(i)+1}^{f l b(1)} \sum_{p=1}^{t s(n)} \lambda(n, p) A(1, t s(n)) A(1, f u m b(n)) \times \\
\left.\sum_{q=1} \sum_{r=1}^{t s(q)} L(q, r) \prod_{t=f d m b(q)}^{i-1}\left(1-\boldsymbol{X}_{s t}\right) A(f d m b(q), i-1)\right) \\
\text { factor }(2)=\sum_{i=1}^{m b} \boldsymbol{X}_{s i}\left(\sum_{j=1}^{m b} \lambda_{m j} A(i, j) \sum_{k=1}^{i-1} L_{m k} \times\right. \\
A(k+1, i-1) \prod_{l=k+1}^{i-1}\left(1-\boldsymbol{X}_{s i}\right)+ \\
\sum_{n=f l b(1)-f l b(i)-1} \sum_{p=1}^{t s(n)} \lambda(n, p) A(1, t s(n)) \times \\
\left.f u m b(n)) \sum_{q=1}^{i-1} L_{q} \prod_{r=q+1}^{i-1}\left(1-\boldsymbol{X}_{s r}\right) A(1, i-1)\right)
\end{gathered}
$$

$$
\begin{aligned}
& \text { factor }(2)= \\
& \sum_{i=1}^{m b} \boldsymbol{X}_{s i}\left(\left\{\sum_{k=1}^{b l b(i)} \sum_{l=1}^{t s(k)} \lambda(k, l) A(1, l)+\sum_{w=1}^{i-1} \lambda_{w}\right\} * A(1, \beta-1) \times\right. \\
& \left.\left\{\sum_{n=f l b(1)-f l b(i)+1}^{f l b(i)} \sum_{p=1}^{t s(n)} L(n, p)+\sum_{v=i+1}^{m b} L_{m v}\right\}\right)
\end{aligned}
$$

$$
\begin{aligned}
& A(i, j)= \\
& \quad \begin{cases}1, & \text { if no protective objct in position } i \text { to } j \\
0, & \text { otherwise. }\end{cases}
\end{aligned}
$$

The value of this function is a binary variable. If $A(i, j)$ equals (1), it means that there is no protective device between branches $i$ and $j$. The meaning of zero value of $A(i, j)$ is the existence of the protective devices at least in one of the sections between branches $i$ and $j$.

Factor (1) is related to the fraction of total restorative energy recover at lateral branches when a short circuit occurs in the sections of the main or the lateral branches. There are two main terms in this factor. One of them concerns with the lateral branches recovery loads when short circuit occurs at the sections of the main branch. The other is relevant to those loads which recovering when fault occurs at lateral branches. When $\boldsymbol{X}_{i}$ is (1), it means that one switching device is allocated at section I and the ability to recover the portion of interrupted customers.

Factor (2) is similar to factor (1). This factor however indicates the portion of the recovery energy installed in the lateral branches.

Factor (3) is of a different nature. It refers to the maneuver effect of the considering feeder by neighboring feeders. The maneuver between distribution feeders can increase the system reliability and reduce the interruption duration.

\section{OPTIMIZATION OF THE OBJECTIVE FUNCTION}

Good position to allocate switches in distribution systems relate to optimum value of RI The self-evident result of the optimization of RI is the switch allocation in each section of the main branch. To lead good solution to real optimum state, some constrains should be added. In (6) the objective function with constrains and additional terms are shown.

The additional term to the objective function corresponds to the penalty coefficient $(M)$. This term leads the optimum result to the basic feasible solution in which the number of switches is minimized.

Maximization of energy restoration or the above objective function is a nonlinear programming problem. To solve this problem, intelligent solution technique is useful. Ref $[5,11]$ use ant colony system as an optimizer. In $[6,8]$ reactive tabu-search is used to solve the problem. Another optimization methods used in papers is genetic algorithms as proposed in $[2,7,9]$. In this paper, genetic algorithm is used to solve nonlinear programming for the maximization of the energy restoration in distribution systems.

Each chromosome used in genetic algorithm has $(n)$ genes. $(n)$ is equal to the number of sections of main feeder branch. Genes are binary variables. When the value of $m^{\text {th }}$ gene is (1), there is a switching device in the $m^{\text {th }}$ section of main branch. In Fig. 1 the typical chromosome is shown. 
Table 1. Component data for analyzed feeder

\begin{tabular}{|c|c|c|c|c|c|c|c|c|c|c|c|c|c|c|c|}
\hline $\begin{array}{c}\text { Number } \\
\text { of } \\
\text { branch }\end{array}$ & $\begin{array}{c}\text { Installed } \\
\text { load } \\
(\mathrm{kVA}) \\
\end{array}$ & $\begin{array}{c}\text { Length } \\
(\mathrm{m})\end{array}$ & $\begin{array}{c}\text { Failure } \\
\text { rate } \\
\text { (F/year) }\end{array}$ & $\begin{array}{l}\text { Number } \\
\text { of } \\
\text { branch }\end{array}$ & $\begin{array}{c}\text { Installed } \\
\text { load } \\
(\mathrm{kVA}) \\
\end{array}$ & $\begin{array}{l}\text { Length } \\
(\mathrm{m})\end{array}$ & $\begin{array}{l}\text { Failure } \\
\text { rate } \\
\text { (F/year) }\end{array}$ & $\begin{array}{c}\text { Number } \\
\text { of } \\
\text { branch }\end{array}$ & $\begin{array}{c}\text { Installed } \\
\text { load } \\
(\mathrm{kVA})\end{array}$ & $\begin{array}{l}\text { Length } \\
(\mathrm{m})\end{array}$ & $\begin{array}{c}\text { Failure } \\
\text { rate } \\
\text { (F/year) }\end{array}$ & $\begin{array}{c}\text { Number } \\
\text { of } \\
\text { branch }\end{array}$ & $\begin{array}{c}\text { Installed } \\
\text { load } \\
(\mathrm{kVA}) \\
\end{array}$ & $\begin{array}{c}\text { Length } \\
(\mathrm{m})\end{array}$ & $\begin{array}{l}\text { Failure } \\
\text { rate } \\
\text { (F/year } \\
\end{array}$ \\
\hline 1 & 0 & 80 & 0.016 & 47 & 0 & 500 & 0.1 & 93 & 0 & 1000 & 0.2 & 139 & 200 & 120 & 0.024 \\
\hline 2 & 0 & 50 & 0.01 & 48 & 0 & 630 & 0.126 & 94 & 0 & 30 & 0.006 & 140 & 0 & 220 & 0.044 \\
\hline 3 & 50 & 400 & 0.08 & 49 & 50 & 10 & 0.002 & 95 & 50 & 500 & 0.1 & 141 & 100 & 10 & 0.002 \\
\hline 4 & 0 & 500 & 0.1 & 50 & 200 & 600 & 0.12 & 96 & 0 & 350 & 0.07 & 142 & 0 & 220 & 0.044 \\
\hline 5 & 250 & 50 & 0.01 & 51 & 200 & 10 & 0.002 & 97 & 50 & 100 & 0.02 & 143 & 0 & 40 & 0.008 \\
\hline 6 & 0 & 400 & 0.08 & 52 & 0 & 130 & 0.026 & 98 & 315 & 50 & 0.01 & 144 & 0 & 120 & 0.024 \\
\hline 7 & 0 & 100 & 0.02 & 53 & 200 & 15 & 0.003 & 99 & 315 & 300 & 0.06 & 145 & 200 & 40 & 0.008 \\
\hline 8 & 200 & 200 & 0.04 & 54 & 500 & 100 & 0.02 & 100 & 200 & 300 & 0.06 & 146 & 0 & 60 & 0.012 \\
\hline 9 & 315 & 80 & 0.016 & 55 & 250 & 60 & 0.012 & 101 & 50 & 630 & 0.126 & 147 & 50 & 15 & 0.003 \\
\hline 10 & 0 & 230 & 0.046 & 56 & 200 & 450 & 0.09 & 102 & 0 & 10 & 0.002 & 148 & 50 & 240 & 0.048 \\
\hline 11 & 100 & 210 & 0.042 & 57 & 0 & 190 & 0.038 & 103 & 0 & 50 & 0.01 & 149 & 0 & 200 & 0.04 \\
\hline 12 & 25 & 400 & 0.08 & 58 & 250 & 350 & 0.07 & 104 & 0 & 60 & 0.012 & 150 & 200 & 240 & 0.048 \\
\hline 13 & 0 & 1050 & 0.21 & 59 & 0 & 180 & 0.036 & 105 & 0 & 50 & 0.01 & 151 & 0 & 330 & 0.066 \\
\hline 14 & 0 & 20 & 0.004 & 60 & 0 & 180 & 0.036 & 106 & 100 & 15 & 0.003 & 152 & 200 & 1600 & 0.32 \\
\hline 15 & 0 & 20 & 0.004 & 61 & 500 & 350 & 0.07 & 107 & 0 & 180 & 0.036 & 153 & 0 & 250 & 0.05 \\
\hline 16 & 50 & 300 & 0.06 & 62 & 100 & 50 & 0.01 & 108 & 0 & 40 & 0.008 & 154 & 200 & 150 & 0.03 \\
\hline 17 & 0 & 40 & 0.008 & 63 & 0 & 160 & 0.032 & 109 & 250 & 60 & 0.012 & 155 & 315 & 250 & 0.05 \\
\hline 18 & 0 & 370 & 0.074 & 64 & 0 & 350 & 0.07 & 110 & 250 & 200 & 0.04 & 156 & 100 & 60 & 0.012 \\
\hline 19 & 50 & 15 & 0.003 & 65 & 100 & 50 & 0.01 & 111 & 0 & 15 & 0.003 & 157 & 0 & 180 & 0.036 \\
\hline 20 & 200 & 100 & 0.02 & 66 & 0 & 15 & 0.003 & 112 & 100 & 15 & 0.003 & 158 & 50 & 150 & 0.03 \\
\hline 21 & 0 & 10 & 0.002 & 67 & 100 & 180 & 0.036 & 113 & 100 & 140 & 0.028 & 159 & 0 & 400 & 0.08 \\
\hline 22 & 0 & 30 & 0.006 & 68 & 200 & 360 & 0.072 & 114 & 200 & 230 & 0.046 & 160 & 0 & 500 & 0.1 \\
\hline 23 & 0 & 30 & 0.006 & 69 & 100 & 420 & 0.084 & 115 & 0 & 10 & 0.002 & 161 & 100 & 10 & 0.002 \\
\hline 24 & 0 & 100 & 0.02 & 70 & 200 & 240 & 0.048 & 116 & 0 & 50 & 0.01 & 162 & 0 & 900 & 0.18 \\
\hline 25 & 200 & 50 & 0.01 & 71 & 160 & 120 & 0.024 & 117 & 100 & 120 & 0.024 & 163 & 0 & 60 & 0.012 \\
\hline 26 & 100 & 210 & 0.042 & 72 & 500 & 210 & 0.042 & 118 & 0 & 10 & 0.002 & 164 & 200 & 850 & 0.17 \\
\hline 27 & 0 & 420 & 0.084 & 73 & 0 & 70 & 0.014 & 119 & 25 & 350 & 0.07 & 165 & 0 & 70 & 0.014 \\
\hline 28 & 315 & 80 & 0.016 & 74 & 100 & 300 & 0.06 & 120 & 0 & 370 & 0.074 & 166 & 0 & 30 & 0.006 \\
\hline 29 & 0 & 150 & 0.03 & 75 & 0 & 20 & 0.004 & 121 & 0 & 360 & 0.072 & 167 & 0 & 450 & 0.09 \\
\hline 30 & 100 & 420 & 0.084 & 76 & 200 & 250 & 0.05 & 122 & 0 & 40 & 0.008 & 168 & 50 & 450 & 0.09 \\
\hline 31 & 160 & 450 & 0.09 & 77 & 160 & 240 & 0.048 & 123 & 0 & 30 & 0.006 & 169 & 0 & 150 & 0.03 \\
\hline 32 & 100 & 10 & 0.002 & 78 & 0 & 120 & 0.024 & 124 & 0 & 50 & 0.01 & 170 & 50 & 50 & 0.01 \\
\hline 33 & 400 & 220 & 0.044 & 79 & 100 & 240 & 0.048 & 125 & 200 & 150 & 0.03 & 171 & 50 & 200 & 0.04 \\
\hline 34 & 0 & 10 & 0.002 & 80 & 315 & 160 & 0.032 & 126 & 100 & 310 & 0.062 & 172 & 0 & 120 & 0.024 \\
\hline 35 & 315 & 150 & 0.03 & 81 & 200 & 120 & 0.024 & 127 & 0 & 200 & 0.04 & 173 & 100 & 210 & 0.042 \\
\hline 36 & 315 & 340 & 0.068 & 82 & 0 & 380 & 0.076 & 128 & 100 & 300 & 0.06 & 174 & 200 & 260 & 0.052 \\
\hline 37 & 400 & 200 & 0.04 & 83 & 100 & 15 & 0.003 & 129 & 500 & 150 & 0.03 & 175 & 50 & 300 & 0.06 \\
\hline 38 & 0 & 250 & 0.05 & 84 & 25 & 70 & 0.014 & 130 & 0 & 120 & 0.024 & 176 & 0 & 200 & 0.04 \\
\hline 39 & 0 & 50 & 0.01 & 85 & 200 & 300 & 0.06 & 131 & 0 & 130 & 0.026 & 177 & 0 & 30 & 0.006 \\
\hline 40 & 0 & 350 & 0.07 & 86 & 0 & 140 & 0.028 & 132 & 100 & 10 & 0.002 & 178 & 100 & 250 & 0.05 \\
\hline 41 & 0 & 360 & 0.072 & 87 & 200 & 10 & 0.002 & 133 & 100 & 400 & 0.08 & 179 & 0 & 15 & 0.003 \\
\hline 42 & 0 & 100 & 0.02 & 88 & 100 & 330 & 0.066 & 134 & 160 & 420 & 0.084 & 180 & 100 & 8 & 0.0016 \\
\hline 43 & 425 & 140 & 0.028 & 89 & 0 & 140 & 0.028 & 135 & 0 & 60 & 0.012 & 181 & 250 & 120 & 0.024 \\
\hline 44 & 0 & 10 & 0.002 & 90 & 250 & 550 & 0.11 & 136 & 0 & 150 & 0.03 & 182 & 0 & 20 & 0.004 \\
\hline 45 & 0 & 40 & 0.008 & 91 & 0 & 5 & 0.001 & 137 & 0 & 150 & 0.03 & 183 & 200 & 250 & 0.05 \\
\hline 46 & 0 & 40 & 0.008 & 92 & 200 & 570 & 0.114 & 138 & 200 & 120 & 0.024 & & & & \\
\hline
\end{tabular}

Table 2. Additional considered assumptions and constraints for real life 183-bus feeder

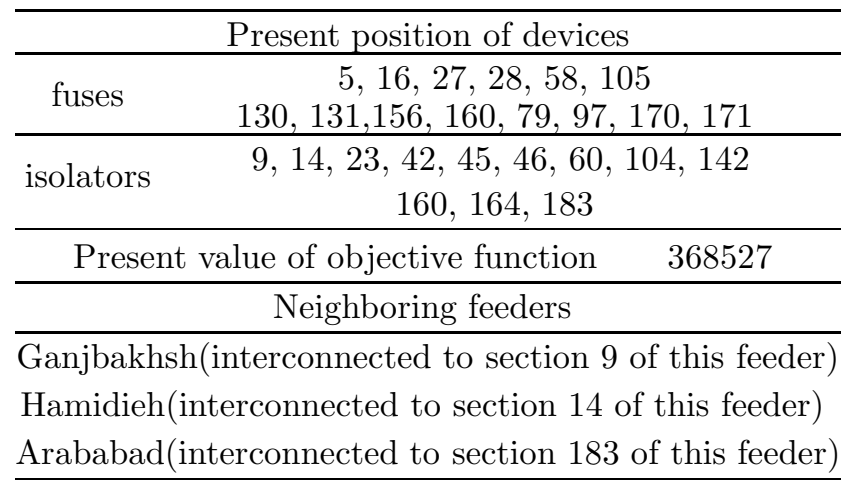

\section{\begin{tabular}{|l|l|l|l|l|l|l|l|l|l|l|}
\hline 0 & 0 & 1 & 0 & 1 & $\ldots \ldots \ldots \ldots . .$. & 0 & 0 & 1 & 0 \\
\hline
\end{tabular}}

Fig. 1. Scheme to represent typical chromosome in genetic algorithm

Table 3. Alternative solutions obtained with the implemented methodology

\begin{tabular}{cc}
\hline \multicolumn{2}{c}{ Proposed alternative solution } \\
\hline Number of the proposed isolators & 12 \\
\hline Positions of the isolators & $\begin{array}{l}9,14,183,43,44,52,54, \\
104,129,144,177,179\end{array}$ \\
\hline $\begin{array}{c}\text { The optimum value of the } \\
\text { objective function }\end{array}$ & 608610 \\
\hline The optimum value of R.I & 788610 \\
\hline
\end{tabular}




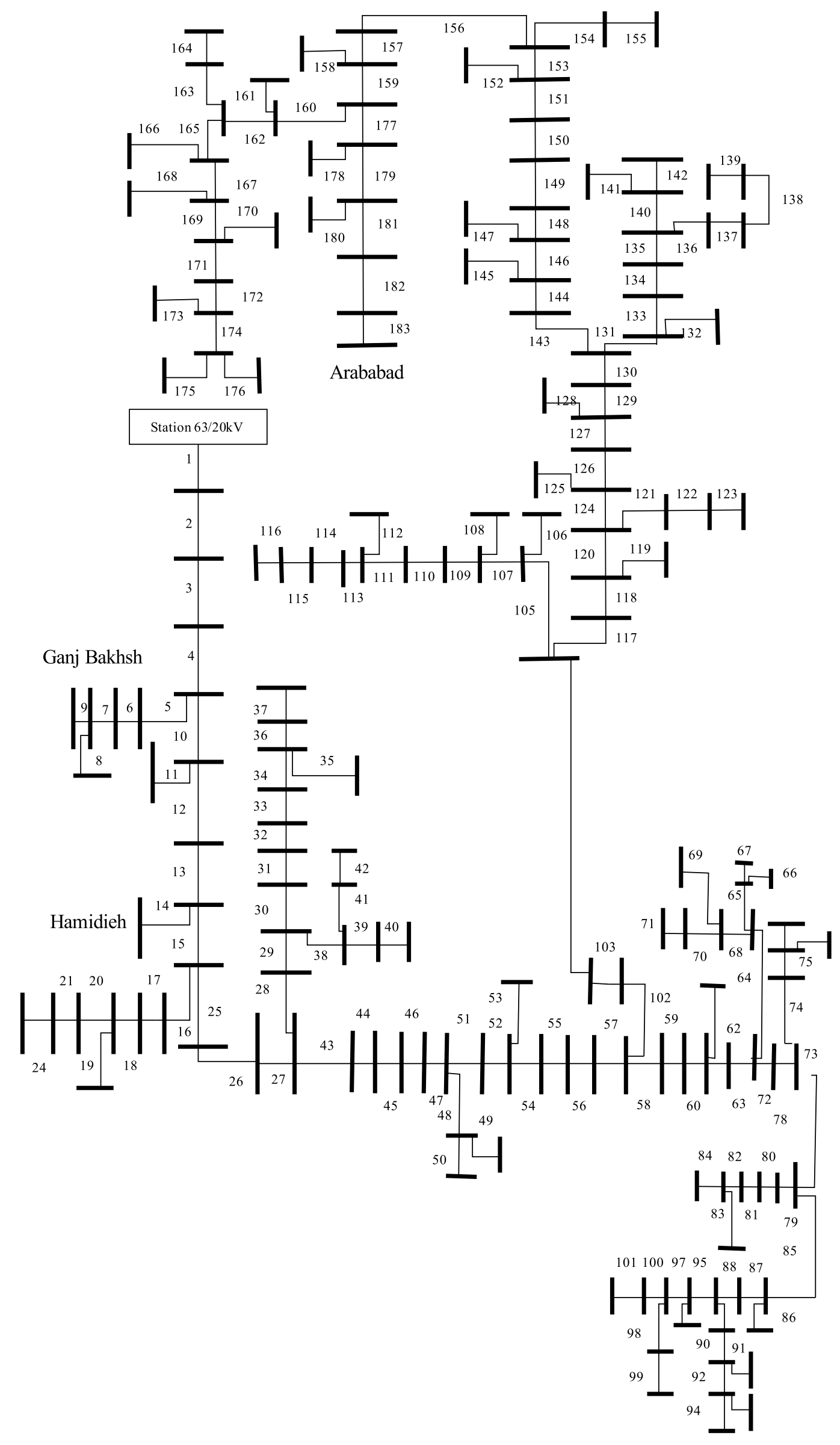

Fig. 2. 183-Bus real life distribution system 


\section{TESTS AND RESULTS}

The actual development and tests are focused on the placement of the switching devices in the overhead radial distribution feeders.

The proposed technique has been applied to a $20 \mathrm{kV}$, real life 183-bus feeder. This feeder is a part of Karaj distribution network. It has two interconnection lines and two neighboring feeders. Permanent and temporary fault rates used in the test are $0.02 \& 0.8$ faults $/\left(\mathrm{km}_{\mathrm{year}}{ }^{-1}\right)$ respectively. Component data for analyzed feeder is described in Table 1.

The considered assumptions and constraints for real life 183-bus feeder are as follows:

There is one circuit breaker between buses 1 and 2 (first section of the main branch). It is assumed that the neighbor feeders can feed total load of intentioned feeder. Since these feeders can feed total load of intentioned, this assumption is feasible. Therefore, there is no problem to provide the energy needed.

There are 7 fuses, 12 isolators and one recloser in this feeder. Recloser is allocated in the first branch and the positions of the fuses and isolators are given in Table 2 .

There are three points to interconnect this feeder to its neighboring feeders. These points are demonstrated in Table 2 .

Comparing the results obtained by the implemented methodology with those of the present condition presents the advantages of applying this method to the distribution feeders. The present feeder condition is presented in Table 2. The difference between the optimum value of the objective function and the value of the present feeder condition is 240083. This increase in energy restoration is achieved by the installation of 9 isolators in proper positions of the distribution feeder. Concerning the other aspect of the optimization, ie lowering the cost, is should be mentioned that, as confirmed by the Tables 2 and 3, the proposed method has lead to desired results and the costs have decreased.

\section{CONCLUSION}

This paper presents an optimization technique for the placement of switches in electric power distribution systems. R.I index has been introduced. This index is relevant to restorative energy in distribution systems when faults occur in distribution feeders. A novel mathematical method is developed to calculate the index. To simplify the calculations of the equations in R.I, an auxiliary function is used. By optimizing the R.I, optimal placement of the switches has been obtained. During the optimization process, to prevent the solution from evident conditions, the penalty factor $(\mathrm{M})$ is used. This coefficient guides the best solution to minimize the number of switches required. GA (genetic algorithm) has been used to optimize the objective function. The method has been applied to a real distribution system and the obtained results illustrate the effectiveness of the proposed method.

\section{Appendix}

$m b \quad$ : number of sections of the main branch

$\lambda_{m i} \quad$ : Failure rate of the section (i) from the main branch

$\lambda(s, p) \quad$ : Failure rate of the section $(\mathrm{p})$ from $s^{\text {th }}$ lateral branch

$N_{m i} \quad$ : Number of customers for section (j) from the main branch

$f l b(i)$ : First downstream lateral branch of section (i) from the main branch

$N(s, p)$ : Number of customers for section (p) from the $s^{\text {th }}$ lateral branch

$t s(s) \quad$ : Number of the sections from the $s^{\text {th }}$ lateral branch

$b l b(i) \quad$ : First upstream lateral branch of section (i) from the main branch

$f d m b(i)$ : First downstream main branch for $i^{\text {th }}$ lateral branch

$f u m b(i)$ : First upstream main branch for $i^{\text {th }}$ lateral branch

\section{REFERENCES}

[1] BILlintON, R.-ALLAN, R. N.: Reliability Evaluation of Power System, Plenum Press, New York, USA, 1984.

[2] SOUDI, F.-TOMASOVIC, K. : Optimal Trade-off in Distribution Protection Design, IEEE Trans. on Power Delivery 16 No. 2 (Apr 2001), 292-296.

[3] SOUDI, F.-TOMASOVIC, K. : Optimized Distribution Protection using Binary Programming, IEEE Trans. on Power Delivery 13 No. 1 (Jan 1998), 218-224.

[4] CELLI, G.-PILO, F. : Optimal Sectionalizing Switches Allocation in Distribution Networks, IEEE Trans. on Power Delivery 14 No. 3 (July 1999), 1167-1172.

[5] TENG, J.-LIU, Y.: A Novel ACS-Based Optimum Switch Relocation Method, IEEE Trans. on Power Systems 18 No. 1 (Feb 2003), 113-120.

[6] SILVA, L. G. W.-PEREIRA, R. A. F.-ABBAD, J. R.MANTOVANI, J. R. S. : Optimised Placement of Control and Protective Devices in Electric Distribution Systems through Reactive Tabu Search Algorithm, Electric Power System Research 78 (Apr 2008), 372-381.

[7] SILVA, L. G. W.-PEREIRA, R. A. F.-MANTOVANI, J. R. S.: Allocation of Protective Device in Distribution Circuits using Nonlinear Programming Models and Genetic Algorithms, Electrical Power System Research (2004).

[8] SILVA, L. G. W.-PEREIRA, R. A. F.-MANTOVANI, J. R. S.: Optimised Allocation of Sectionalizing Switches and Protection Devices in Distribution Networks by using Reactive Tabu Search Algorithm, in 18th International Conference of Electric Distribution, Turin, 2005.

[9] SILVA, L. G. W.-PEREIRA, R. A. F.-MANTOVANI, J. R. S.: Otimized Allocation of Sectionalizing Switches and Control and Protection Devices for Reliability Indices Improvement in Distribution Systems, in 2004 IEEE/PES Transmission \& Distribution Conference \& Exposition, Latin America, 2004.

10] BILlintON, R.-JONNAVITHUlA, S. : Optimal Switching Device Placement in Radial Distribution Systems, IEEE Trans. on Power Delivery 11 No. 3 (July 1996), 1646-1651.

11] TIPPACHON, W.-RERKPREEDAPONG, D.: Multiobjective Optimal Placement of Switches and Protective Devices in Electric Power Distribution Systems using ant Colony Optimization, Electric Power System Research 79 (Mar 2009), 1171-1178.

Received 21 June 2011 
Hamed Hashemi Dezaki was born in 1986, Borujen, Iran. He received BS degree in electrical engineering from Amirkabir University of Technology, Tehran, Iran in 2009. Presently, he is an MSc student at the department of electrical engineering of Amirkabir University of Technology, Tehran, Iran. His main fields of research are power system transient and protection of power systems, power quality, high voltage, reliability, electrical insulation.

Hossein Askarian Abyaneh was born in Abyaneh, Isfahan on March 20, 1953. He received the BS and MS degree both in Iran in 1976 and 1982 respectively. He also received another MS degree and PhD from UMIST, Manchester, UK in 1985 and 1988 respectively, all in electrical power system engineering. He published over 140 scientific papers in international journals and conferences. Currently, he is a Professor with the Department of Electrical Engineering and Head of the Electrical Engineering Department, AUT, Iran, working in the area of the relay protection and power quality.

Ali Agheli was born in 1985, Tehran, Iran. He received BS degree in electrical engineering from Amirkabir University of Technology, Tehran, Iran in 2008. Presently, he is an MSc student at the department of electrical engineering of Amirkabir University of Technology, Tehran, Iran. His main fields of research are power system transient and protection of power systems, high voltage, electrical insulation.

Kazem Mazlumi was born in Tehran, Iran in 1976. He received the BS degree in electrical engineering from Amirkabir University of Technology, Tehran, Iran, in 2000, the MS degree from Sharif University, Tehran, Iran, in 2003, the PhD from Amirkabir University of Technology, Tehran, Iran, in 2009. He is currently an assistant professor with Zanjan University, Zanjan, Iran.

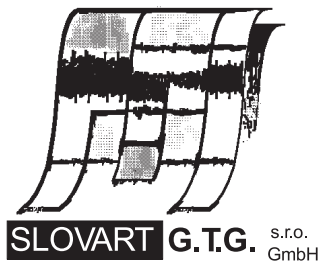

EXPORT - IMPORT
EXPORT - IMPOR T

of periodicals and of non-periodically printed matters, books and CD-ROMs

Krupinská 4 PO BOX 152, 85299 Bratislava 5, Slovakia tel: ++421 263839 472-3, fax: ++421263839485 info@slovart-gtg.sk; http://www.slovart-gtg.sk

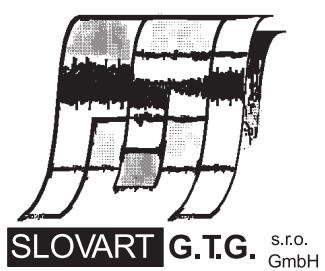

EXPORT - IMPORT 